\title{
The Challenges in Adopting Assistive Technologies in the Workplace for People with Visual Impairments
}

\author{
Herman Wahidin \\ Interaction Design Lab, School of \\ Computing \& Information Systems \\ The University of Melbourne \\ Melbourne, VIC, Australia \\ hwahidin@student.unimelb.edu.au
}

\author{
Jenny Waycott \\ Interaction Design Lab, School of \\ Computing \& Information Systems \\ The University of Melbourne \\ Melbourne, VIC, Australia \\ jwaycott@unimelb.edu.au
}

\author{
Steven Baker \\ Interaction Design Lab, School of \\ Computing \& Information Systems \\ The University of Melbourne \\ Melbourne, VIC, Australia \\ steven.baker@unimelb.edu.au
}

\begin{abstract}
There are many barriers to employment for people with visual impairments. Assistive technologies (ATs), such as computer screen readers and enlarging software, are commonly used to help overcome employment barriers and enable people with visual impairments to contribute to, and participate in, the workforce. However, recent research suggests it can be difficult for people with visual impairments to effectively adopt and implement ATs in the workplace. This paper reports insights from interviews with five professional workers with visual impairments. The interviews revealed that each participant had adopted different configurations of ATs, which they used in various ways to support their work. In addition, all participants followed a complex process to successfully select, learn, and integrate these tools into their work activities. During this process, they faced challenges, such as the need to educate colleagues to make shared documents more accessible. We conclude that despite progress in the development and use of ATs, there remains a need for future work that addresses these accessibility issues to support collaborative work between people with visual impairments and their sighted colleagues.
\end{abstract}

\section{CCS CONCEPTS}

- Human-centered computing $\rightarrow$ Accessibility technologies - Social and professional topics $\rightarrow$ Assistive technologies

\section{KEYWORDS}

Visual impairment, workplace, assistive technology

\section{ACM Reference format:}

Herman Wahidin, Jenny Waycott, and Steven Baker. 2018. The Challenges in Adopting Assistive Technologies in the Workplace for People with Visual Impairments. In Proceedings of the $30^{\text {th }}$ Australian

Permission to make digital or hard copies of all or part of this work for personal or classroom use is granted without fee provided that copies are not made or distributed for profit or commercial advantage and that copies bear this notice and the full citation on the first page. Copyrights for components of this work owned by others than ACM must be honored. Abstracting with credit is permitted. To copy otherwise, or republish, to post on servers or to redistribute to lists, requires prior specific permission and/or a fee. Request permissions from Permissions@acm.org.

OzCHI '18, December 4-7, 2018, Melbourne, VIC, Australia

(C) 2018 Association for Computing Machinery.

ACM ISBN 978-1-4503-6188-0/18/12...\$15.00

https://doi.org/10.1145/3292147.3292175
Computer-Human Interaction Conference (OzCHI '18). ACM Press, New York, NY, 11 pages. https://doi.org/10.1145/3292147.3292175

\section{Introduction}

In 2015, there were approximately 4.3 million Australians living with a disability, according to data from Australian Bureau of Statistics [4]. This number is equivalent to $18.3 \%$ or nearly a fifth of the Australian population. A disability can create barriers for people to access health care, social services, education, and to participate in employment [48]. Anyone who has experienced unemployment will understand that it can have a significant negative impact on psychological and social wellbeing. According to a large-scale study by Milner and colleagues, these negative effects can be particularly strong for those living with a disability [28]. However, some of the barriers to unemployment for persons with a disability can be overcome with the use of assistive technologies (ATs) [9,18,38], such as mobility aids, screen magnifiers, and screen readers for people with visual impairments [19].

According to the Employment Research Survey in 2012 [40], people with visual impairments are four times as likely to be unemployed compared to the general population. Therefore, ATs are needed to enhance the participation of people with visual impairments in the workforce. The utilisation of ATs for people with visual impairments is particularly important given that sight is crucial for many work activities, such as access to print materials and computer systems [30]. Indeed, a survey of over 600 visually impaired people by Vision Australia found that $94 \%$ of people with visual impairments use ATs in their jobs [40].

There are numerous ATs available to support the use of computers and software in office-based employment [19]. However, recent research shows barriers still exist that make some tools, such as screen readers, difficult to use across contexts [5]. For instance, there are social barriers to their effective use in collaborative settings [6], screen readers also have difficulty accessing websites [26] and describing image-rich content on social media sites [29]. Billah et al. [5] argue that we still have a long way to go before people with visual impairments have ubiquitous access to digital technologies.

In response to this concern, we conducted an in-depth interview study that aimed to understand how people with visual impairments use ATs to support their work. The study 
aimed to better understand the factors that will need to be addressed in order to improve collaborative work in the future. Building on a growing body of research in this area $[5,6]$, we examined how people with visual impairments go about integrating ATs into their work practices. To frame our research, we adapted key elements of Kintsch and dePaula's widely referenced AT adoption framework [24]. Specifically, we investigated the following research questions: (1) What are the types and the functionalities of ATs being used? (2) What are the experiences, including the difficulties, in adopting ATs in the workplace? We found that our participants used unique configurations of ATs to support their particular needs and faced a number of challenges during the adoption process. Participants described ongoing accessibility challenges, often due to the limitations of screen readers in accessing graphs, images, certain layouts, styles, and formats within office documents. They also spoke of the challenges associated with educating their colleagues about collaborative work practices that relate to those accessibility issues.

Below, we discuss previous research in this area before describing our study methods and findings in more detail. We conclude that accessibility in the workplace remains an ongoing challenge for people with visual impairments. Technology developers, employers, and employees need to respond to this challenge. As well as increasing awareness of accessibility issues among sighted colleagues, we argue that there is a need for further work to address the accessibility problems and improve collaborative practices in the workplace.

\section{Related Work}

Different types of disabilities require different types of AT to overcome functional limitations [2]. This applies also to people with visual impairments who require a specific AT based on the severity of their impairment [19]. According to the International Classification of Diseases-10 (ICD-10), the definition of visual impairment is people with low vision or blindness [46].

Two components are used to determine visual impairments: visual acuity and visual field. Visual acuity is the ability to see objects clearly and sharply from a distance. The test for visual acuity uses a visual chart that contains several lines of capital letters in different sizes. The standard normal sight is if a person can read the letters on 6 metres' line within 6 metres distance. This normal visual acuity is called $6 / 6$ or $20 / 20$ (6 metres or 20 feet). On the other hand, the visual field is the ability to see surroundings by looking straight forward. The normal visual field value is 170 degrees [36].

Based on those two components, World Health Organization (WHO) has defined: (1) low vision as visual acuity of less than $6 / 18$ but equal to or better than $3 / 60$, or a visual field of less than 20 degrees; and (2) blindness as visual acuity of less than $3 / 60$, or a visual field of less than 10 degrees [45]. Another term that is used by the Australian government is legally blind. It means a person who has a visual acuity of $6 / 60$ or less, and/or a visual field of less than 10 degrees [36].
The types of AT that can be used in the workplace by people with visual impairments are explained by Hersh and Johnson [19]. They describe the AT types in detail by following these employment categories: professional and person-centred, scientific and technical, administrative and secretarial, skilled and unskilled (manual) trades, and outdoor work. This information asserts that ATs can improve the work participation of people with visual impairments in a wide range of professions.

\subsection{AT Challenges}

Prior studies have identified some challenges regarding the use of ATs by people with visual impairments. Billah et al. [5] highlight several problems in using different screen readers across platforms: (1) Lack of shortcuts standardisation; (2) Lack of portable settings that work on different operating systems; and (3) Remote access systems that are poorly supported. These findings revealed that screen readers need major improvements before they can provide ubiquitous access to people with visual impairments.

For many modern work activities, websites provide access to essential information and tasks. However, many developers do not follow Web Content Accessibility Guidelines (WCAG) and this has an effect on how ATs work. An analysis of Australian government agency websites conducted as part of the National Transition Strategy (NTS) reported that at the end of 2014, only $39 \%$ of new websites conformed to WCAG 2.0 [20]. The large number of inaccessible websites created frustration among people with visual impairments [26]. Moreover, social media, such as Twitter also pose problems to screen readers because of embedded images; these are becoming increasingly common with users incorporating emoticons and gifs in twitter messages [29].

Albusays et al. [1] investigated the challenges faced by programmers with visual impairments. The study found that the navigation difficulties were encountered when the participants used their coding software with the ATs, it slowed their speed and introduced mistakes. In an in-depth study of workplace accessibility, Branham and Kane [6] examined both the use and non-use of ATs by workers with visual impairments in a collaborative office space. Branham and Kane's participants reported that they chose not to ask their colleagues about AT problems and they lacked awareness of office resources, such as emergency signage, posters, and desk phones. Branham and Kane also found that there were distinct differences in the types of accessibility problems noted by interviewees with visual impairments, compared with the problems identified by their sighted colleagues. The study revealed that people with visual impairments employed a number of strategies to maintain accessibility and ensure they were able to work effectively alongside sighted colleagues.

Branham and Kane's study [6] provides a rich depiction of the challenges faced by people with visual impairments when working in a collaborative environment. In the study presented below we extend this work by focusing on understanding how people with visual impairments go about adopting and using 
The Challenges in Adopting Assistive Technologies in the Workplace for People with Visual Impairments

ATs in the workplace and identifying the difficulties encountered during this process. In order to understand the adoption process, we have adapted a framework developed by Kintsch and DePaula [24] that describes the process of AT adoption, as described below.

\subsection{AT Adoption}

Kintsch and DePaula's framework of AT adoption [24] describes how ATs should be adopted for use in daily life. It was derived from a review of empirical studies and direct observations. The authors argue that the framework can be used to avoid the abandonment of AT by defining the successful attributes of each stakeholder in each phase. Even though the purpose of the framework is for daily life, the iterative phases in the framework (see Figure 1) can be applied to the workplace environment. The framework describes four phases of AT adoption: development, selection, learning, and integration.

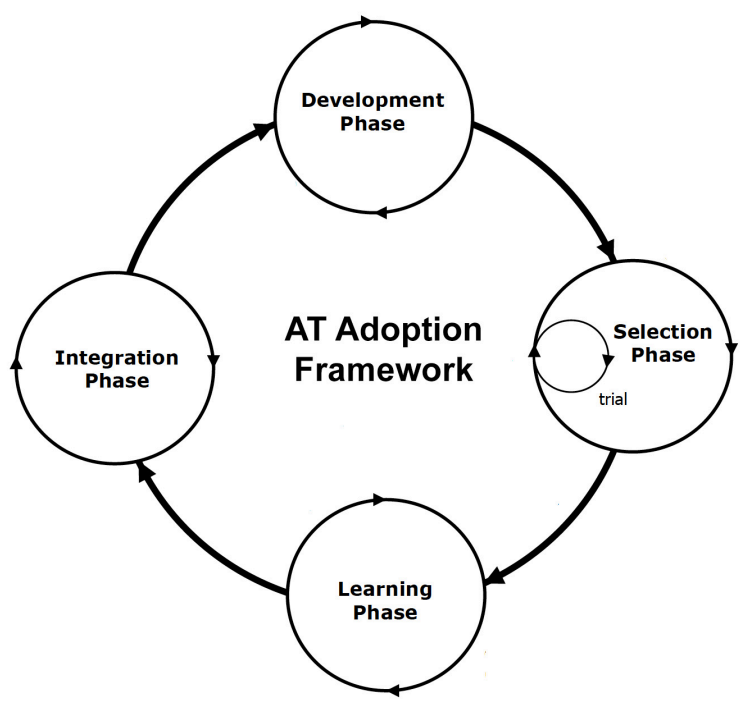

Figure 1: AT Adoption Framework [24].

2.2.1 Development Phase. This refers to the process of developing the assistive technologies, a phase undertaken by technology developers. In the development phase, one of the difficulties is to accommodate different conditions of disability from moderate to severe [12,32]. However, some researchers have proposed a systematic usability evaluation to overcome this issue with a user-centred approach $[12,33,34]$. Choi and Sprigle [12] assert that a short evaluation survey could engage the users with the developers in the design process of assistive devices. In addition, the developers should be aware of and position themselves from a user's point of view as argued by Williams et al. [47]. They found that sighted people are likely to misunderstand how a person navigates without vision and this could impact to the design of the AT navigation device.

2.2.2 Selection Phase. Kintsch and dePaula advocate for a team-based approach during the selection phase, involving the user, family and friends, and employers. During this phase the user, along with other stakeholders, chooses appropriate ATs to suit their purposes. An AT assessment conducted by an AT specialist could help people with disabilities to select the right tool for their jobs [17]. Moreover, the involvement of employers in the assessment process is needed to ensure the AT benefits align with employer expectations [16]. During the assessment, the information about the AT that is already used by the user could give some insights, as well as the observation of user's interests and abilities [21].

2.2.3 Learning Phase. During the learning phase, the user learns how to use the assistive technology. Kintsch and dePaula suggest that caregivers should be well-trained in using the device, and then should teach the user how to use it. This advice may not be people with some disabilities who are likely to learn to use the assistive technologies independently, without the support of caregivers. Nevertheless, learning is a continuous process and essential to increase work productivity [13]. For instance, users who use ATs to access computers will have to deal with software updates and learn some new features [3]. In this case, users need to keep learning and upgrading their skills and familiarity with the new features of ATs. To support this process, it is important for the users to be able to access resources on the internet. For people with visual impairments, ATs allow them to undertake self-learning via the internet, while also instigating iterative learning in response to software updates [19].

2.2.4 Integration Phase. This phase refers to "integrating a new device into daily activities" [24, p. 8]. When integrating ATs into a work setting, workplace support for the ATs will be important. Driscoll et al [16] identified five success factors towards AT integration: (1) The interplay between the user, the colleagues, and the employers should involve positive attitudes; (2) The commitment to support AT use and awareness of its use; (3) The involvement of the user in the decision of AT-related matters; (4) The provision of AT specialists in troubleshooting; and (5) The accommodating work environment. Moreover, a clear workplace policy should be implemented as well as conducting training to all employees regarding the diversity in the company [8].

Kintsch and dePaula's [24] AT adoption framework has been widely referenced in research that has examined the use of ATs by people with disabilities in a range of settings [11,35,49]. The framework has been critiqued for its suggestion that people with disabilities should learn to use and adapt to the technology, rather than having ATs designed to adapt to the user [23]. The framework does not specifically address AT adoption in the workplace, and is broadly applied to a range of disabilities, including cognitive disabilities, rather than focusing specifically on the adoption and use of ATs by people with visual impairments. Therefore, some of the assertions in this framework - such as the emphasis on the role of caregivers in selecting and learning to use ATs - are not relevant to our study. In particular, the development phase focuses on the role of technology developers in designing new ATs. 
Table 1: Profile of the participants.

\begin{tabular}{|c|c|c|c|c|c|c|c|}
\hline & Age & Gender & $\begin{array}{l}\text { Vision } \\
\text { Condition }\end{array}$ & $\begin{array}{l}\text { Current } \\
\text { Position }\end{array}$ & Responsibility & $\begin{array}{l}\text { Years at } \\
\text { Current } \\
\text { Company }\end{array}$ & AT Use \\
\hline P1 & 60 & Female & $\begin{array}{l}\text { Totally Blind } \\
\text { since birth }\end{array}$ & $\begin{array}{l}\text { General } \\
\text { Manager }\end{array}$ & $\begin{array}{l}\text { Community } \\
\text { Relations }\end{array}$ & 1.5 & $\begin{array}{c}\text { Screen Reader (Windows), } \\
\text { Electronic Braille, } \\
\text { VoiceOver (iOS) }\end{array}$ \\
\hline P2 & 47 & Female & $\begin{array}{l}\text { Low Vision } \\
\text { since birth }\end{array}$ & $\begin{array}{l}\text { Administration } \\
\text { Officer }\end{array}$ & $\begin{array}{l}\text { General office } \\
\text { processes }\end{array}$ & 6.5 & $\begin{array}{l}\text { Eyeglasses, CCTV, } \\
\text { Enlarging Software } \\
\text { (Windows) }\end{array}$ \\
\hline P3 & 53 & Male & $\begin{array}{l}\text { Totally Blind } \\
\text { since age } 1\end{array}$ & $\begin{array}{l}\text { Research } \\
\text { Professor }\end{array}$ & $\begin{array}{l}\text { Coordinate } \\
\text { research projects }\end{array}$ & 7 & $\begin{array}{l}\text { Screen Reader (Linux), } \\
\text { Electronic Braille, } \\
\text { VoiceOver (iOS) }\end{array}$ \\
\hline $\mathbf{P 4}$ & 46 & Female & $\begin{array}{l}\text { Low Vision } \\
\text { (Legally Blind) } \\
\text { since age } 23\end{array}$ & $\begin{array}{l}\text { Independent } \\
\text { Consultant }\end{array}$ & $\begin{array}{l}\text { Improve disability } \\
\text { inclusion }\end{array}$ & $\begin{array}{c}\text { Self- } \\
\text { Employed }\end{array}$ & $\begin{array}{c}\text { Screen Reader and } \\
\text { Enlarging Software } \\
\text { (Windows), Electronic } \\
\text { Braille }\end{array}$ \\
\hline P5 & 51 & Female & $\begin{array}{l}\text { Totally Blind } \\
\text { since age } 22\end{array}$ & $\begin{array}{l}\text { Contract } \\
\text { Helpdesk }\end{array}$ & $\begin{array}{l}\text { Training and tech } \\
\text { support }\end{array}$ & $\begin{array}{c}\text { Self- } \\
\text { Employed }\end{array}$ & $\begin{array}{c}\text { Screen Reader (Windows), } \\
\text { Electronic Braille, } \\
\text { VoiceOver (iOS) }\end{array}$ \\
\hline
\end{tabular}

In our study, we did not examine the perspective of technology developers and have therefore excluded this phase from our analysis. Nevertheless, the framework provides a useful articulation of the process by which ATs are adopted into daily life. We have adapted this perspective as an analytical framework for understanding the experiences of the five professional workers with visual impairments who took part in our study.

\section{Methods}

This study aimed to examine the use of ATs in the workplace for people with visual impairments and investigate the challenges faced in the AT adoption process (selection, learning, and integration). We conducted an in-depth interview study using semi-structured interviews so as to allow us to interrogate the subjective responses of the participants and explore the reasons behind their opinions [27]. The study used a communication strategy that followed tips recommended by Vision Australia [41], a leading national provider of people with visual impairments in Australia. The project received approval from the university's Human Ethics Committee (ID 1749385).

\subsection{Participants}

Recruitment was conducted using a snowball sampling technique. One of the advantages of this technique was that it ensured the selected participants were closely related to the topic and that they were more likely to have relevant insights and understanding about the phenomena under investigation [31]. We aimed to recruit participants who were professional workers with visual impairments (low vision or blindness) who lived in our local city and used ATs in their jobs. The first participant was a personal contact who fitted the criteria and who agreed to be part of the study. Via this participant, we were introduced to an advocacy organisation for people with visual impairments that had an employee who was also willing to be a participant. This second participant was subsequently able to assist us to connect with three further participants, one of whom was recruited via an assistive technology mailing list. All participants were contacted by email to arrange the interview time and venue.

We recruited five participants for this research, consisting of one male and four females who were aged between 46 and 60 years old. They reported varied vision conditions; two had low vision, while the others experienced total blindness. The participants spanned a range of occupations, including administration officer, independent consultant, contract helpdesk, general manager, and research professor. Their profiles can be seen in Table 1. All participants had worked for more than 20 years and had used ATs since their first job.

\subsection{Data Collection}

The interview questions were open-ended and were divided into four headings: (1) Background Profile: to gather the user's profiles, working experience, and disability conditions; (2) Assistive Technology: to gather the AT types, the functionalities, and the acquiring process; (3) Usability: to gather the AT benefits and challenges, the user experiences, and the suggestions for improvement, and; (4) Workplace: to gather information about the workplace support, the barriers in collaborating with colleagues, and other ATs that could be used in the workplace.

Interviews were audio-recorded and transcribed, and each interview took around 1.5 to 2 hours. The interviews were faceto-face and were conducted in venues that were chosen by the 
participants, such as the office, their home, or a café. Two participants were interviewed at their offices, this enabled us to get some insights into their working environment, the placement of ATs in those environments, and their interactions with the ATs.

The interview questions were piloted with one participant and modified accordingly. A range of ancillary materials were also collected: (1) Photos of the participant's AT; (2) Our observations on the placement and use of ATs, and; (3) Technical information about the ATs being used, gathered from the vendor's website.

\subsection{Data Analysis}

After the interview data were collected, the audio-recordings were transcribed verbatim. The transcripts were analysed using NVivo qualitative data analysis software and followed a thematic analysis technique. This technique enabled us to observe the patterns within data and allowed us to see different aspects relevant to the research topic [7]. During the analysis, the three authors discussed the initial categories and generated themes and sub-themes based on the similarity and the occurrence of the issues reported by the participants. The thematic analysis was driven by the two research questions. In answering the first question (What are the types and functionalities of ATs being used in the workplace?), we focused on identifying common types of AT being used and participants' preferences. From this data on ATs, we then classified them based on the functionalities and platforms. Four main categories were identified: magnifiers, screen readers, braille technology, and smartphones. In response to the second question (What are the experiences, including difficulties, in adopting ATs in the workplace?), we mapped the data to three phases in the AT adoption framework (selection, learning, and integration), and identified sub-themes within each phase. For example, in the integration phase of AT adoption, we defined three sub-themes: workarounds, educating colleagues, and workplace environment.

\section{Findings}

There are two main themes in the findings: the types of AT use (e.g. magnifiers, screen readers, braille technology) and the AT adoption experiences (selection, learning, and integration). The comments from the participants are labelled using a numbered coding system (e.g. P1, P2, etc.) based on participants' profile in Table 1.

\subsection{Types of AT Use}

AT products for people with visual impairments can be divided into those designed for people with low vision and people who are blind. However, people with low vision may still use a screen reader that is a product for blind users as explained by P5. So, according to P5 in the industry of AT for people with visual impairments, there are usually people who use magnification, or people who use speech, and some people who use speech also use braille. This categorisation is based on the underlying technology; however, in presenting the types of AT use below, we divide it into types of the devices or the software that the participants used.

4.1.1 Magnifiers. Magnifiers in general are used by people with low vision to magnify or zoom something so it can be seen more clearly. Two participants in the study, P2 and P4, used magnifier ATs. Both had different preferences in magnifier ATs; while P2 used magnification technology as her primary AT, P4 preferred to primarily use speech and only used magnification if she needed to; for example, to see a diagram or outline of an image. These variations can be largely attributed to the fact that P2's vision was better than P4's who was classified as being legally blind.

P2 used both low-tech (manual) and high-tech (electronic/software) magnifiers. The low-tech magnifiers that P2 used were eyeglasses that have bifocal lenses and a handheld magnifier. For high-tech magnification, P2 used a Closed-Circuit Television (CCTV) which is also called an electronic magnifier. This device enables P2 to do her job in the office, such as reading invoices and telephone bills which often contain small and faint writing.

Another high-tech magnification that P2 used was enlarging software. This kind of software allows selective magnification and improves readability and orientation by allowing users to change cursor's size, text and background colour. She used three kinds of enlarging software applications. The first was Lightning PLUS, a portable enlarging software in a USB stick that she can plug into any Windows computers. The second was ZoomText, a powerful enlarging software that also supports speech. Using this software, P2 could change the size and the colour of the mouse pointer, which enables her to locate the mouse easily when she moves around the screen. The third enlarging software was a built-in Windows application called Magnifier.

4.1.2 Screen Readers. Screen reader applications can read out loud not only the content on the computer screen but also the underlying code that allows users to interact and navigate through it. Screen readers enable people with visual impairments to access computers and complete multiple tasks, such as working with Office programs, email, and the internet.

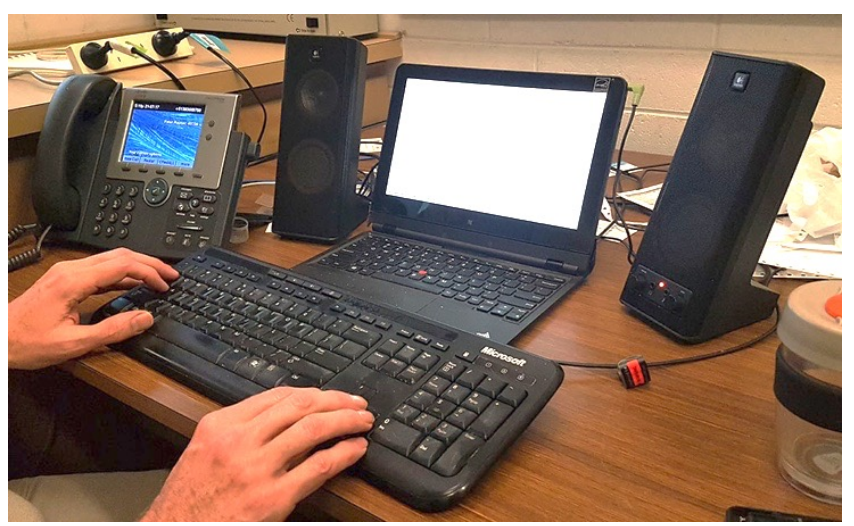

Figure 2: Screen reader desk setup. 
The Challenges in Adopting Assistive Technologies in the Workplace for People with Visual Impairments

Four of participants in this study used screen readers as their main ATs: P1 and P4 used JAWS, P5 used Window-Eyes, and P3 used ORCA and Emacspeak. JAWS and Window-Eyes are commercial applications while ORCA and Emacspeak are opensource applications that run under Linux. P1 and P4 were pleased with JAWS, because they could change the settings (e.g. read the text or read sentences or spell out words). Both P5 and P3 described their screen readers as 'powerful'. When asked to describe his screen reader, P3 commented:

"So, it's... you can highlight... it uses pitch and volume and so on... in the same way that visual systems use font and colour. It's a very beautiful piece of code...” (P3)

4.1.3 Braille Technology. Braille is a specialised method of reading and writing for people with visual impairments. The method uses a tactile form that consists of six dot pins arranged in two columns of three. The combination of these six dots can represent the alphabet, numbers, and punctuation [42]. For P5, braille was a paramount skill that she had learnt since she was seven when she gradually lost her sight.

"Braille is absolutely essential for me because it's a form of literacy. I could listen to screen readers, I could listen to tape recorders, I could listen to... but braille is truly literacy." (P5)

Braille can be used for various types of applications, from low-tech (e.g. braille typewriters) to high-tech (e.g. braille displays). P5 used a range of braille technologies. She had a braille manual typewriter that she used almost every day to make labels, a braille printer or embosser, a braille watch, a braille display, and a braille notetaker. P1 and P3 also used a braille embosser, but they rarely use it now because they preferred to use electronic braille. This electronic braille uses refreshable dot pins and usually has eight dots in a cell rather than 6 dots, where the additional two dots enable it to have 256 braille patterns [15]. The four participants who used screen readers (P1, P3, P4, and P5), also had electronic braille devices. This is because electronic braille devices can communicate with screen readers. For example, a screen reader can generate speech, and in the meantime, will give the same code to be translated to braille when an electronic braille device is connected to the computer.

4.1.4 Smartphones. In addition to specialised ATs, as smartphone technology has developed, both Android (Google) and iOS (Apple) have embedded accessibility features into their products. For example, there are built-in screen readers, such as VoiceOver for Apple's iPhone devices and TalkBack for Android devices. Both of them also support magnification and options to make the icons and fonts larger [43].

Two of the participants, P2 and P4, were using Android smartphones (Samsung). However, even though they used the magnification features, they were primarily using their smartphones for phone calls. The rest of the participants owned iPhone smartphones and used them more extensively as AT devices. This included connecting their iPhones to a braille display for taking notes and some other things, such as accessing the calendar, GPS navigation, and reading e-books. P1 described her increasing use of her iPhone in the following way:

"I can read the newspapers that come through every day, I can read my books, I can... people can send me things. So, I do a lot on the phone." (P1)

4.1.5 Other ATs. In addition to the types of AT use noted above, there was a selection of other ATs that were used by the participants. These ATs were not the primary AT used in doing the job tasks, but they do have functionalities that can support the participants in the workplace.

- OCR (Optical Character Reader) that can convert printed materials, scanned documents, and image-based PDF files to text documents.

- Audio Player and Recording that can be used for taking notes or recording a meeting.

- Talking GPS that is used to navigate and help them to travel.

- Long White Cane that can help in detecting obstacles when they are walking.

\subsection{AT Adoption Experiences}

The phases in this section were based on the AT adoption framework, but the categories of each phase were defined based on the data analysis. Through the thematic analysis we identified the following categories within each phase: (1) The selection phase consisted of: assessment, funding, and training; (2) The learning phase encompassed: accessibility, compatibility, keeping up-to-date, and troubleshooting; (3) The integration phase, included: workarounds, educating colleagues, and workplace environment.

4.2.1 Selection Phase. All the participants, except P3, had experience in using JobAccess and Vision Australia services. JobAccess is the national hub that provides support and information for disability employment, funded by Australian Government Department of Social Services [22]. Vision Australia is a service partner of JobAccess that provides assessment and assistance services. It is a non-profit organisation that has 28 centres across Australia [44]. These two organisations had helped the participants at every step of the selection phase.

Assessment: In selecting the ATs that would be used in the workplace, four participants (P1, P2, P4, P5) explained that they received an assessment from Vision Australia through JobAccess. P3 did not use any assessment service because he could get the information about ATs through the university and online communities. He also did not need JobAccess funding which usually would require some assessments. His AT needs were usually provided by his employers or from his research grants.

Funding: A major goal of the assessment process that the participants went through was to get financial support from JobAccess. The funding involves the employer first paying for the ATs before being reimbursed by JobAccess. This funding option is also available for self-employed people as explained by $\mathrm{P} 4$. Moreover, a positive aspect of the JobAccess funding is the 
AT items will become the person's belongings and can be carried to another job.

Training: The participants usually received training when they used the AT products for the first time. They could request the training from JobAccess and then either Vision Australia or the vendor of the ATs would provide the training. P4 explained that she had completed a lot of training before, including JAWS training. However, once she acquired a good basic knowledge, she was able to continue learning by herself. For people who have the technical background, AT knowledge can be selfacquired via practice, user guides, accessing an email discussion list, or online discussion forums. This self-training method was preferred by $\mathrm{P} 1, \mathrm{P} 5$, and $\mathrm{P}$.

4.2.2 Learning Phase. Whereas formal training was part of the initial selection phase, the learning phase describes a more continuous process required to maintain the use of ATs. Over the course of their employment, participants had to overcome a number of challenges, which required considerable self-learning. These relate to accessibility, compatibility, keeping up-to-date, and troubleshooting.

Accessibility: Some accessibility issues were raised by the participants who used screen readers. The most common accessibility problem relates to the fact that screen readers cannot read images, diagrams, and graphs. For Word documents, there are some styles and formats that cannot be read by screen readers, such as text boxes, flowcharts, and edit fields. Similar accessibility issues can affect Excel documents, as described by P1:

"Excel sheet can be okay, it depends on the structure of the complexity of the Excel. Sometimes you have Excel's cells embedded within cells and pull-down menu, so they can be tricky."

PowerPoint documents were generally accessible to the participants as long as the content like a diagram or a graph, had a note that described it.

Participants reported a range of common accessibility issues with PDF documents. These related to the fact that the scanned image as PDF is inaccessible to screen readers, except by using OCR (Optical Character Reader) software.

Besides the accessibility issues within Office and PDF documents, many inaccessible websites were also reported by the participants. According to P3, 50\% of websites that he accessed were not fully accessible and around 25\% were not accessible at all. P3 expressed frustration that web developers did not follow the standard accessibility guidelines which would address many of these issues.

"So, I'd say my largest single barrier is inaccessible websites. So, it's not necessarily a fault of technology is simply a fault of the interaction between the way the people design websites. So, I would reckon that... half of them... half the websites in the world pose problems... about a quarter, I can't use at all." (P3)

The web accessibility issues that have been identified by participants were page layout, unlabelled buttons, mouse-over, and pop-ups. Furthermore, some of these web issues were not only faced by screen reader users, but also by P2, a screen magnifier user. P2 reported that if a website has menu items at the very bottom of the page, she can miss out completely.

Compatibility: In using the ATs, the participants sometimes encountered compatibility issues between their screen reader or magnification software and the main program they were using. P5 stated that sometimes her screen reader conflicts with the Word program and she does not know what causes it. Her only option is to restart the program. P2 discussed a similar issue with ZoomText. She described how ZoomText clashed with Internet Explorer. This was a major problem as Internet Explorer was the only compatible browser to access her office portal. The way she did to resolve this issue was to close ZoomText and switch to Microsoft's own Magnifier software.

Another compatibility issue reported by P3 related to the dominance of Microsoft Office that most people used over LibreOffice, his preferred office software. He used LibreOffice because he was a Linux user and Microsoft did not make any Office products for Linux.

Keeping Up-to-date: Participants reported numerous issues related to keeping their ATs up-to-date. This is particularly challenging as software gets any updates, the ATs that are used to access the software should also be updated. P4 explained that every time the Microsoft does the update, she has to learn some new commands and has to update her JAWS. P5 also described her experience when she had to move from Office 2003 to 2013. At that time, she had to learn two things: the new concepts of the Office ribbons, and how to use those ribbons with the screen reader.

With the exception of the issues noted above, participants in this study described being generally able to stay up-to-date with their ATs. P1 explained that she reads manuals and if she needs additional help, she will contact someone she knows or the Vision Australia helpdesk. P4 related a similar preference for 'self-teaching':

"I can self-teach... to top-up my skills or to update... as Windows updates and JAWS updates, I know enough to guess or to do research for individual things. So, I haven't had any Vision Australia training for... maybe it could... six or seven years... yeah, and I've just learnt on the job." (P4)

Troubleshooting: When asked about troubleshooting their ATs, most of the participants described trying to fix it by themselves by reading user manuals, and only if this failed, contacting the office IT staff, vendor's helpdesk, Vision Australia helpdesk, or asking their family members to help. P5, who worked as a helpdesk person, stated that she was expected to be able to solve other people's technical problems. If she was encountering a problem she could not solve herself, she discussed the issues with her colleagues or other tech support people within her company. P3, who used open source ATs, had the advantage of direct access to the developers of his screen readers, the ORCA and the Emacspeak. He would simply contact the developers through online discussion forums if needed. This ease of access to the developers for open-source software was 
The Challenges in Adopting Assistive Technologies in the Workplace for People with Visual Impairments

one of the benefits that P3 explained over the commercial products of screen readers.

4.2.3 Integration Phase. This section examines the experiences of the participants in interacting with their workplace and colleagues when using their ATs. Three aspects that will be discussed: workarounds, educating colleagues, and workplace environment.

Workarounds: In doing their work activities, the participants described sometimes needing to do things differently to manage a specific limitation; we refer to this as a workaround. P3 described an interesting self-made workaround experience when he hired a young programmer to create a program to meet his needs. This program enables him to read the numerical data of a graph (e.g. weather maps) through frequency sounds by touching the monitor screen.

P5 provided a more typical workaround example. When her office introduced a new CRM (Customer Relationship Management) system, all the staff received the training. But her network manager, who was sighted, used too many visual metaphors, such as 'click here' or 'drag that'. To work around these issues, P5 arranged for separate training on the new CRM from a blind person in the company.

P2's vision condition meant she saw an image like a negative photo. To address issues related to her negative photo perception, when creating ID cards for her organisation's members, she often changed the members' photo to reverse contrast first to make sure the photo and the position were good, and changed it back again afterwards.

Educating Colleagues: Participants described the importance of educating colleagues to make them understand the limitations of ATs. For example, P5 explained that she had to educate her head office to design an accessible Excel spreadsheet. P1 provided another example of this approach:

"You know... at my office, people tend to do complex diagrams to talk about something and then I can't read them. So, it's about trying to get people in our office to make their documents accessible, that's always a challenge." (P1)

P2 described her frustration in not being able to see what her colleagues wanted her to see by just pointing to something without describing it.

"I guess the only thing that happens is sometimes when you get other people who aren't vision impaired, they... they say things like 'Oh have a look at this', you know, and... or they'll be showing you something on their computer and they'll point and say 'see this', and you said 'no, I can't see that', you have to describe it to me, you

know, talk what you're looking at, talk it through or 'it's over

there'... what is that, where is over there, what's over there. So, you have to teach them." (P2)

Workplace Environment: Participants spoke of how a supportive workplace environment can contribute to the effectiveness of their AT use. P4 described that when she was working for a university, the employer supported her in arranging the office, she got a long desk that allowed her to put electronic magnifier, computer, and braille notetaker. Similarly, P3 described how he negotiated a smaller office space that was more personal so that he could learn the space and arrange his ATs more effectively.

In addition to having a supportive workplace, P2 highlighted the importance of being able to access funding for workplace modifications (via JobAccess) and the availability of specialist support services. P4 provided an example of the latter in relation to Guide Dogs Australia:

“(A) Guide Dogs Australia orientation mobility instructor came out and (provided training around a) travel route to and from work (and) around the workplace... They do cane instruction as well as dog instruction." (P4)

\section{Discussion}

Through an in-depth interview study, this research investigated the types of AT being used by people with visual impairments to support their work practices, and examined how people with visual impairments go about adopting ATs for use in the workplace. Our findings revealed that people choose to use particular configurations of ATs to meet their needs, depending on their visual impairment condition, workplace environment, and compatibility with other software used.

In addition, we found that the process of adopting ATs for use in the workplace is an ongoing iterative process that involves learning, troubleshooting, developing workarounds, and educating colleagues. While the selection phase of AT adoption was straightforward, participants described a number of challenges they faced in the later phases of the adoption process. Below, we discuss these findings in more detail and consider the lessons that can be drawn for future research and development so as to improve accessibility in the future collaborative workplace.

\subsection{Configurations of AT}

The two ATs that participants mainly used to access the computer and do their jobs were screen magnifiers and screen readers. Participants described the screen reader software as 'powerful' and noted that some functions were particularly well designed; one participant described the aural cues which his screen reader used to create emphasis, thereby communicating features of written text that would normally be hidden from people with visual impairments.

While there was some commonality in the ATs used, participants made use of different combinations of ATs and emphasised particular features and functions that were important to them. For instance, braille technology was particularly important to P5 who was blind and had learnt to use braille at the age of seven. In addition, electronic braille devices were valued by participants who used screen readers, because the devices worked well together. Overall, while a range of AT items were useful for participants to support their jobs, the ATs that directly related to their collaborative work with colleagues 
(e.g. accessing documents, emails, and internet) seemed to be particularly important for them.

\subsection{Challenges in Using AT}

With regard to the experiences in the selection phase, there were no issues reported by the participants. Participants said they were able to easily go through all the steps in the selection phase (assessment, funding, and training). Fortunately, the role of a government program, JobAccess, had helped the participants to overcome the barriers in acquiring the ATs. Those barriers according to some studies are the lack of knowledge regarding AT options [10], the concerns of employers regarding the cost of the ATs [39], and the lack of proper assessment from AT specialists [17].

However, some issues were reported by the participants in the learning phase. These issues have been categorised into accessibility, compatibility, keeping up-to-date, and troubleshooting. Concerns about compatibility and keeping upto-date align with a study by Arthanat et al. [3] that identified the needs of AT users to manage software updates and compatibility issues when using ATs to access computers. In our study, participants reported managing the compatibility issues by restarting the program or replacing with the compatible AT software. While participants were able to address this challenge to continue to work effectively, it was still an inconvenient process that created an accessibility barrier. Participants also reported how they managed keeping up-to-date and troubleshooting; they could self-teach or ask others to help if needed.

The part of the learning phase that seemed to be the most significant challenge for the participants was the accessibility issues. The fact that screen readers cannot read images, diagrams, and graphs causes this problem. This finding echoes concerns raised by research recently published in the humancomputer interaction field that found the increasing use of images in Twitter makes it inaccessible to people with visual impairments [29]. Besides this limitation, some styles, formats, and layouts within Microsoft Office documents (Word, Excel, PowerPoint), PDF files, and websites also posed problems for our participants. These problems with website accessibility have remained constant for over a decade, as they were reported in the British Disability Rights Commission Report in 2004 [14]. Meanwhile, for screen magnifier user, the accessibility issue occurred in the layout of websites; participant reported missing content if it was placed at the area where the magnifier tool cannot reach (e.g. at the very bottom of the screen).

In discussing the integration phase, three aspects were revealed by the participants: workarounds, educating colleagues, and workplace environment. In the workarounds, the findings showed the capabilities of the participants to do things differently but deliver the same results. They were therefore able to contribute effectively in the workplace, but may have had to overcome obstacles, through workarounds, to achieve their goals. All participants reported experiencing a positive workplace environment; their employers or JobAccess had helped them to establish office set ups that suited their needs.
Educating colleagues was closely related to the accessibility issues in the learning phase. The ATs that participants used, such as screen readers, were not perfect and created some problems for collaborative work with sighted colleagues. Participants therefore had to remind their colleagues about the need for documents to be made accessible so they could be properly read by screen readers. All the participants agreed that educating and reminding their sighted colleagues to ensure effective collaborative work would always be a challenge. This finding supports Branham and Kane's [6] conclusion that mixedability workplaces need to consider both the technical and social approaches in order to solve accessibility problems.

\subsection{Improving Accessibility}

From participants' experiences in the AT adoption process, we highlighted two main challenges that participants faced: accessibility issues and educating colleagues. To address these ongoing challenges around accessibility and collaboration, sighted colleagues need to be made aware of the issues faced by people with visual impairments who use ATs, such as screen readers. With this awareness, sighted colleagues may willingly check their shared documents to ensure the accessibility. While website accessibility is also a major problem that participants experienced, we emphasise here that improved accessibility of shared documents is crucial and needs to be better supported in the future to ensure people with visual impairments are able to fully and fairly participate in collaborative work.

The process of checking a document's accessibility can be done manually or by using the built-in feature within the Office program or separate software. Studies in the area of humancomputer have examined web accessibility checker tools [25,37], but further research needs to be done to examine the accessibility checker tools for Office and PDF documents to determine whether these tools provide an effective avenue for supporting collaborative work in mixed-ability workplaces.

\subsection{Limitations and Future Work}

This study encountered limitations that may limit the generalisability of the findings. First, all the participants in this study had working experience for more than 20 years, indicating they were proficient in AT adoption within the workplace and at some degree could be categorised as success stories. The challenges that they had in using the ATs in the workplace may be different from those novice workers with visual impairments who only have one or two years working experience.

Second, this study involved a small number of participants. While a study of this size may have limited generalisability, this was an in-depth study that involved lengthy interviews with each participant and yielded rich information about our participants' individual experiences adopting and using ATs in the workplace. The scale of this study follows similar in-depth research on this topic [e.g., 6] and is partly a reflection of the challenges involved in recruiting participants from a small and specific community (i.e., people with visual impairments who use ATs in the workplace). Nevertheless, further research may 
be necessary to include a larger group of participants and their sighted colleagues to gain further insights regarding accessibility challenges for collaborative work.

Based on the findings reported in this paper, we argue that there is significant opportunity for further research and development to improve accessibility in the workplace, particularly around the use of shared documents. As Billah et al. [5] argue much work remains to be done to ensure people with visual impairments maintain access to digital technologies and resources. Future work needs to investigate the ease of use and the effectiveness of existing accessibility checker tools for Office and PDF documents. Problems identified in using accessibility checker tools can then be addressed through development or improvement of new technologies and with further consideration of the social issues affecting mixed-ability workplaces.

Other future work that could be done is to develop an AT adoption framework in the context of the workplace environment. We believe this framework will be very useful to identify the stages, the stakeholders, and the attributes for success in implementing AT in the workplace, which will improve the experience and participation of people with disabilities in the workforce.

\section{Conclusion}

The use of ATs is essential for people with visual impairments to have an equal access to employment. This paper investigated the challenges that people with visual impairments might have in adopting ATs in the workplace. Following an analysis of the types of AT being used and the AT adoption experiences, three central themes were identified: (1) The ATs that directly related to the collaborative work seemed to be particularly important; (2) In regards to accessibility problems, both technical and social approaches need to be considered in mixed-ability workplaces; (3) Improved accessibility of shared documents is crucial and needs to be better supported in the future. These findings emphasised the accessibility issues within collaborative work practices. Therefore, the research presented in this paper provides a foundation for researchers and technology developers to conduct further work to address the accessibility problems and improve collaborative work between people with visual impairments and their sighted colleagues.

\section{ACKNOWLEDGMENTS}

We acknowledge Australia Awards that provided the first author with the scholarship for his master's degree. We would like to thank our participants for their time and valuable contributions.

\section{REFERENCES}

[1] Khaled Albusays, Stephanie Ludi, and Matt Huenerfauth. 2017. Interviews and Observation of Blind Software Developers at Work to Understand Code Navigation Challenges. In Proceedings of the 19th International ACM SIGACCESS Conference on Computers and Accessibility, 91-100.
[2] Sandra Alper and Sahoby Raharinirina. 2006. Assistive technology for individuals with disabilities: A review and synthesis of the literature. F. Spec. Educ. Technol. 21, 2 (2006), 47-64.

[3] Sajay Arthanat, Kasey Lesner, and Vidya Sundar. 2016. An evaluation framework to measure usability of Assistive Technology at workplace: A demonstration study. 7. Vocat. Rehabil. 44, 2 (2016), 213-226.

[4] Australian Bureau of Statistics. 2016. 4430.0 - Disability, Ageing and Carers, Australia: Summary of Findings, 2015. Retrieved September 30, 2017 from http://www.abs.gov.au/ausstats/abs@.nsf/Lookup/4430.0main+features202015

[5] Syed Masum Billah, Vikas Ashok, Donald E. Porter, and I. V. Ramakrishnan 2017. Ubiquitous Accessibility for People with Visual Impairments: Are We There Yet? In Proceedings of the 2017 CHI Conference on Human Factors in Computing Systems, 5862-5868.

[6] Stacy M. Branham and Shaun K. Kane. 2015. The invisible work of accessibility: how blind employees manage accessibility in mixed-ability workplaces. In Proceedings of the 17th International ACM SIGACCESS Conference on Computers \& Accessibility, 163-171.

[7] Virginia Braun and Victoria Clarke. 2006. Using thematic analysis in psychology. Qual. Res. Psychol. 3, 2 (2006), 77-101.

[8] Diane Nelson Bryen, Blyden B. Potts, and Allison C. Carey. 2007. So you wan to work? What employers say about job skills, recruitment and hiring employees who rely on AAC. Augment. Altern. Commun. 23, 2 (January 2007) 126-139. DOI:https://doi.org/10.1080/07434610600991175

[9] Tina M. Butterfield and J. Hunter Ramseur. 2004. Research and case study findings in the area of workplace accommodations including provisions for assistive technology: A literature review. Technol. Disabil. 16, 4 (2004), 201210.

[10] Dawn Carlson, Nathaniel Ehrlich, B. Berland, and Nell Bailey. 2001. Assistive technology survey results: Continued benefits and needs reported by Americans with disabilities. Res. Exch. 7, 1 (2001).

[11] Stefan Carmien, Melissa Dawe, Gerhard Fischer, Andrew Gorman, Anja Kintsch, and James F. Sullivan Jr. 2005. Socio-technical environments supporting people with cognitive disabilities using public transportation. ACM Trans. Comput.-Hum. Interact. TOCHI 12, 2 (2005), 233-262.

[12] Young Mi Choi and Stephen H. Sprigle. 2011. Approaches for evaluating the usability of assistive technology product prototypes. Assist. Technol. 23, 1 (2011), 36-41.

[13] Desleigh M. De Jonge and Sylvia A. Rodger. 2006. Consumer-identified barriers and strategies for optimizing technology use in the workplace. Disabil. Rehabil. Assist. Technol. 1, 1-2 (January 2006), 79-88. DOI:https://doi.org/10.1080/09638280500167324

[14] Disability Rights Commission. 2004. The web: access and inclusion for disabled people: a formal investigation. TSO, London.

[15] Judy Dixon. 2007. Eight-dot Braille. Retrieved October 1, 2017 from http://www.brailleauthority.org/eightdot/eightdot.html

[16] Michelle P. Driscoll, Sylvia A. Rodger, and Desleigh M. de Jonge. 2001. Factors that prevent or assist the integration of assistive technology into the workplace for people with spinal cord injuries: Perspectives of the users and their employers and co-workers. f. Vocat. Rehabil. 16, 1 (2001), 53-66.

[17] Mandy J. Gamble, Denetta L. Dowler, and Louis E. Orslene. 2006. Assistive technology: Choosing the right tool for the right job. F. Vocat. Rehabil. 24, 2 (2006), 73-80.

[18] Brad Hedrick, Theresa Louise-Bender Pape, Allen W. Heinemann, Jennifer L. Ruddell, and Janet Reis. 2006. Employment issues and assistive technology use for persons with spinal cord injury. F. Rehabil. Res. Dev. 43, 2 (2006), 185

[19] Marion A. Hersh and Michael A. Johnson (Eds.). 2008. Assistive Technology for Visually Impaired and Blind People. Springer London, London. DOI:https://doi.org/10.1007/978-1-84628-867-8

[20] Scott Hollier. 2014. Web accessibility: Things you need to know. Gov. News 34 1 (2014), 18.

[21] Katherine J. Inge. 2006. Assistive technology as a workplace support. f. Vocat Rehabil. 24, 2 (2006), 67-71.

[22] JobAccess. About JobAccess | Job Access. Retrieved October 17, 2017 from https://www.jobaccess.gov.au/about-jobaccess

[23] Hyun K. Kim, Sung H. Han, Jaehyun Park, and Joohwan Park. 2016. The interaction experiences of visually impaired people with assistive technology: A case study of smartphones. Int. F. Ind. Ergon. 55, (2016), 22-33.

[24] Anja Kintsch and Rogerio DePaula. 2002. A framework for the adoption of assistive technology. SWAAAC 2002 Support. Learn. Assist. Technol. (2002), 110.

[25] Eduard Klein, Anton Bolfing, and Markus Riesch. 2014. Checking web accessibility with the content accessibility checker (CAC). In International Conference on Computers for Handicapped Persons, 109-112.

[26] Jonathan Lazar, Aaron Allen, Jason Kleinman, and Chris Malarkey. 2007. What Frustrates Screen Reader Users on the Web: A Study of 100 Blind Users. Int. 7. Hum.-Comput. Interact. 22, 3 (May 2007), 247-269. DOI:https://doi.org/10.1080/10447310701373063 
[27] Michele J. McIntosh and Janice M. Morse. 2015. Situating and Constructing Diversity in Semi-Structured Interviews. Glob. Qual. Nurs. Res. Vol 22015 (2015).

[28] A. Milner, A. D. LaMontagne, Zoe Aitken, R. Bentley, and Anne M. Kavanagh. 2014. Employment status and mental health among persons with and without a disability: evidence from an Australian cohort study. 7 Epidemiol Community Health (2014)

[29] Meredith Ringel Morris, Annuska Zolyomi, Catherine Yao, Sina Bahram, Jeffrey P. Bigham, and Shaun K. Kane. 2016. With most of it being pictures now, I rarely use it: Understanding Twitter's Evolving Accessibility to Blind Users. In Proceedings of the 2016 CHI Conference on Human Factors in Computing Systems, 5506-5516.

[30] Katherine Nagle. 2001. Transition to employment and community life for youths with visual impairments: Current status and future directions. 7. Vis. Impair. Blind. FVIB 95, 12 (2001).

[31] William Lawrence Neuman. 2014. Social research methods: qualitative and quantitative approaches. Harlow, Essex: Pearson, [2014].

[32] Hugo Paredes, Hugo Fernandes, Paulo Martins, and João Barroso. 2013. Gathering the users' needs in the development of assistive technology: a blind navigation system use case. In International Conference on Universal Access in Human-Computer Interaction, 79-88.

[33] Umesh Persad, Patrick Langdon, and John Clarkson. 2007. Characterising user capabilities to support inclusive design evaluation. Univers. Access Inf. Soc. 6, 2 (2007), 119-135

[34] Ornella Plos, Stéphanie Buisine, Améziane Aoussat, Fabrice Mantelet, and Claude Dumas. 2012. A Universalist strategy for the design of Assistive Technology. Int. f. Ind. Ergon. 42, 6 (2012), 533-541.

[35] Halley P. Profita. 2016. Designing wearable computing technology for acceptability and accessibility. ACM SIGACCESS Access. Comput. 114 (2016), 44-48.

[36] Retina Australia. 2017. Legal Blindness - Retina Australia - fighting blindness. $\begin{array}{llll}\text { Retrieved } & \text { October } & 1, & 2017\end{array}$ http://www.retinaaustralia.com.au/legal_blindness.htm

[37] Sandra Sanchez-Gordon and Sergio Luján-Mora. 2017. A method for accessibility testing of web applications in agile environments. In Proceedings of the 7th World Congress for Software Quality (WCSQ). En proceso de publicación.(citado en la página 13, 15, 85).
[38] Angela L. Sauer, Andra Parks, and Patricia C. Heyn. 2010. Assistive technology effects on the employment outcomes for people with cognitive disabilities: a systematic review. Disabil. Rehabil. Assist. Technol. 5, 6 (2010), 377-391.

[39] Elisabeth B. Simpson, Beth Loy, and Helen P. Hartnett. 2017. Exploring the Costs of Providing Assistive Technology as a Reasonable Accommodation. 7 . Appl. Rehabil. Couns. 48, 2 (2017).

[40] Vision Australia. 2012. Employment Research Survey Report 2012.

[41] Vision Australia. Communicating effectively with people who are blind. $\begin{array}{llll}\text { Retrieved } & \text { October } & 1, & 2017\end{array}$ http://www.visionaustralia.org/services/family-friends-andcarers/communicating-effectively-with-people-who-are-blind

[42] Vision Australia. Braille technologies. Retrieved October 1, 2017 from http://www.visionaustralia.org/learn-more/learning-to-liveindependently/using-technology-and-computers/technology-overview/brailletechnologies

[43] Vision Australia. Accessible mobile phones. Retrieved October 1, 2017 from http://www.visionaustralia.org/learn-more/learning-to-liveindependently/using-technology-and-computers/technologyoverview/accessible-mobile-phones

[44] Vision Australia. Who we are and what we do. Retrieved October 1, 2017 from http://www.visionaustralia.org/about-us/who-we-are-and-what-we-do

[45] WHO. 2007. Global initiative for the elimination of avoidable blindness: action plan 2006-2011. World Health Organization, Geneva.

[46] WHO. 2011. ICD-10: International statistical classification of diseases and related health problems. World Health Organization, Geneva.

[47] Michele A. Williams, Caroline Galbraith, Shaun K. Kane, and Amy Hurst. 2014. Just let the cane hit it: how the blind and sighted see navigation differently. In Proceedings of the 16th international ACM SIGACCESS conference on Computers \& accessibility, 217-224.

[48] World Health Organization. 2015. WHO Global Disability Action Plan, 20142021: better health for all people with disability.

[49] Xiangkui Yao and Stephen Fickas. 2007. Pedestrian navigation systems: a case study of deep personalization. In Proceedings of the 1st International Workshop on Software Engineering for Pervasive Computing Applications, Systems, and Environments, 11 